\title{
PENGARUH KUALITAS PRODUK, HARGA DAN INFLUENCER MARKETING TERHADAP KEPUTUSAN PEMBELIAN SCARLETT BODY WHITENING
}

\author{
Cindy Septia Pratiwi ${ }^{1}$, Agus Purnomo Sidi ${ }^{2}$ \\ Institut Teknologi dan Bisnis Asia Malang ${ }^{1,2}$ \\ Email : agusps@asia.ac.id ${ }^{2}$
}

\begin{abstract}
This research aimed to figure out the influence between product quality, price and marketing influencer with the purchasing decision of Scarlett Body Whitening in East Java. The research instrument employed questionnaire to collect data from Scarlett Body Whitening consumers in East Java. Since there was no valid data for number of the consumers, the research used Roscoe method to take the sample. Data analyzed using multiple linear regression test. Product quality and price have a positive and significant effect on purchasing decisions. Meanwhile, the marketing influencer had no significant effect on purchase decision for Scarlett Body Whitening. Need further research to ensure that marketing influencer had an effect on purchase decision.
\end{abstract}

Keywords: Product quality, price, marketing influencer, buying decision

\begin{abstract}
1.Pendahuluan
Pada saat ini banyak masyarakat dari berbagai kalangan khususnya di Indonesia yang berlomba-lomba mencoba untuk meningkatkan kualitas penampilannya terutama pada warna kulit. Mereka berlomba-lomba ingin memiliki kulit yang bersih dan cerah. Tidak sedikit dari mereka melakukan apa saja untuk membuat kulit seperti yang mereka inginkan contohnya adalah dengan operasi plastik, suntikan hormone progesteron serta suntikan Vitamin C. Akan tetapi tak banyak yang bisa melakukan hal tersebut dikarenakan keterbatasan salah satunya adalah keterbatas biaya yang dimiliki. Oleh sebab itu, tidak sedikit masyarakat yang memilih untuk membuat kulitnya bersih dan cerah dengan beberapa alternatif yang bisa dijangkau oleh semua kalangan seperti mengonsumsi makanan yang mengandung Vitamin $\mathrm{C}$, dan memakai produk pencerah warna kulit seperti lulur, sabun mandi dan krim pencerah
\end{abstract}


kulit. Dengan meningkatnya minat masyarakat terhadap produk pencerah kulit pihak produsen khususnya perusahaan kecantikan terbesar dan ternama memanfaatkan peluang tersebut untuk memproduksi berbagai macam produk pencerah kulit untuk ditawarkan kepada masyarakat.

Berdasarkan data yang tercantum pada hasil survey Zap Beauty Index 2020 dengan persentase tertinggi 69\% masyarakat Indonesia menginginkan produk perawatan dan kecantikan yang dapat mencerahkan kulit mereka. Akan tetapi, dalam memilih suatu poduk perawatan dan kecantikan masyarakat Indonesia memiliki pertimbangan tersendiri dengan adanya perbedaan selera dan pendapatan. Beberapa yang harus dipertimbangkan antara lain adalah kualitas produk dan harga. Beauty Index 2020 menyatakan bahwa hal yang dapat mendorong masyarakat Indonesia memilih suatu produk adalah sebuah review dari produk itu sendiri (Eka Fatin dan Ratih Hasanah, 2020). Review produk dapat diakses melalu berbagai macam sosial media seperti Instagram dan Youtube.

Dari berbagai macam produk pencerah kulit yang ada di pangsa pasar kecantikan Indonesia, penelitian ini lebih berfokus pada obyek Scarlett Body Whitening by Felicia Angelista. Scarlett Body Whitening adalah merk produk pencerah kulit lokal yang diproduksi oleh salah satu public figure ternama Indonesia yaitu Felicya Angelista sejak tahun 2017 di mana merk ini terdapat beberapa produk dengan kandungan dan manfaat yang berbeda.

Scarlett Body Whitening by Felycia Angelista merupakan produk kecantikan yang dapat mencerahkan kulit karena mengandung Glutathione dan Vitamin E yang sangat bagus untuk membuat kulit lebih cerah. Selain itu Scarlett Body Whitening juga sudah memiliki sertifikasi BPOM yang berarti semua produk Scarlett Body Whitening sudah teruji secara klinis sehingga tidak akan membahayakan kulit penggunanya. (scarlettwhitening.com, 2021).

Pada bulan Januari 2021 Scarlett Body Whitening berada di puncak penjualan dengan market share sebanyak 57\% dengan total penjualan mencapai lebih dari RP.7 miliar mengalahkan kompetitornya yang notabenenya merupakan merek internasional. Tidak hanya itu Scarlett Body Whitening juga menempati posisi 
kedua dalam 5 Top Brand di e-commerce Indonesia yang telah berhasil mencapai angka penjualan Rp. 29,78 miliar (compas.co.id, 2021). Dalam akun official di salah satu e-commerce ternama di Indonesia yaitu Shopee, Scarlett Body Whitening mencapai jumlah pengikut sebanyak 1,9 juta dengan tingkat penjualan lebih dari sepuluh ribu pada setiap jenis produknya (Shopee Indonesia, 2021). Serta dalam official akun Scarlett Body Whitening di Instagram mencapai jumlah pengikut 5juta terhitung 31 Oktober 2021 dan telah mendapatkan symbol centang biru (verified account) artinya akun Scarlett Body Whitening telah terbukti keasliannya oleh pihak Instagram.

Dalam memasarkan produknya Scarlett Whitening menggandeng beberapa public figure dan influencer untuk melakukan review dalam media sosial seperti Instagram dan Youtube untuk memperkenalkan dan mempromosikan produk Scarlett Body Whitening. Salah satu influencer tersebut adalah Rachel Vennya atau biasa dikenal dengan panggilan Buna. Rachel Venya merupakan salah satu influencer yang terkenal dengan akun Instagramnya @ rachelvennya dengan jumlah pengikut 6,7juta terhitung 31 Oktober 2021 dan telah memiliki symbol centang biru (verified account) biasanya melakukan review produk Scarlett Body Whitening dalam postingan di Instagramnya untuk mempengaruhi para pengikut dan para masyarakat Indonesia untuk menggunakan Scarlett Body Whitening.

\section{Metode Penelitian}

Dalam penelitian ini peneliti memilih menggunakan jenis penelitian kuantitatif dimana penelitian kuantitatif merupakan salah satu dari beberapa macam penelitian yang perinciannya disampaikan secara sistematis, terencana serta terstruktur dengan jelas. Berdasarkan informasi dari Instagram dilihat pada tanggal 02 Oktober 2021 Kota Malang memiliki reseller resmi Scarlett Body Whitening terbanyak di Jawa Timur. Penelitian ini dilakukan di Kota Malang dikarenakan Kota Malang merupakan salah satu kota pendidikan dan merupakan kota perantauan di Jawa Timur yang masyarakatnya merupakan sebagian besar berasal dari berbagai daerah. Oleh karena itu peneliti tertarik untuk memilih 
Kota Malang sebagai tempat penelitian dilakukan untuk memperoleh data dari berbagai macam responden.

Dikarenakan penelitian ini akan dilakukan di Kota Malang maka populasi dari penelitian ini adalah konsumen Scarlett Body Whitening yang ada di Kota Malang yang tidak diketahui jumlahnya. Penentuan sampel dalam penelitian ini berdasarkan pada teori Roscoe (1975) yang menyatakan bahwa ukuran sampel yang dipilih dalam penelitian adalah antara tiga puluh sampai dengan lima ratus elemen. Oleh sebab itu, peneliti menetapkan jumlah sampel dalam penelitian ini sebanyak 120 responden yang diharapkan dapat memenuhi sebagai pengganti keseluruhan populasi yang telah diteliti.

Terdapat dua jenis data yang digunakan pada penelitian ini yaitu data sekunder dan data primer. Data sekunder dalam penelitian ini diperoleh dari berbagai macam sumber yaitu jurnal penelitian terdahulu, buku, dan referensi internet. Selain itu, peneliti juga menggandeng salah satu reseller resmi Scarlett Body Whitening yang ada di Kota Malang untuk mendapatkan data responden. Sedangkan data primer dalam penelitian ini diperoleh dari kuisioner yang akan dibagikan oleh peneliti kepada responden.

Peneliti melakukan membagikan kuisioner dalam bentuk googleform kepada pengguna produk melalui bantuan reseller resmi Scarlett Body Whitening yang ada di Kota Malang. Selanjutnya reseller akan membagikan kuisioner tersebut kepada konsumennya. Kerjasama dengan reseller ini diharapkan dapat memberikan respon yang lebih cepat dari konsumen.

Setelah data sekunder dan data primer terpenuhi, penulis akan melakukan analisis data primer menggunakan SPSS dengan teknik Analisis Linier Berganda serta Uji Hipotesis Penelitian. Dengan terkumpulnya data primer dan sekunder, peneliti dapat mengolah dan melakukan analisis serta menarik kesimpulan hasil uji hipotesis dari penelitian ini.

Berdasarkan penelitian dari penelitian Tumbel \& Walangitan (2021), Setiawan (2018), Putri et al (2021), Purba (2016), Gunawan \& Agustin (2019) serta Sari \& Hidayat (2021) yang mengangkat pengaruh kualitas produk terhadap keputusan pembelian, peniliti beranggapan bahwa terdapat pengaruh antara 
kualitas produk terhadap keputusan pembelian Scarlett Body Whitening. Selain kualitas produk, harga juga mempengaruhi dari keputusan pembelian sesuai dengan penelitian yang dilakukan oleh Gunawan \& Agustin (2019), Purba (2016), Putri (2021) dan Setiawan (2018).

Faktor yang menjadi perhatian peneliti selain kualitas dan harga produk terhadap pembelian produk adalah faktor marketing influencer. Dimana pengaruh dari marketing influencer yang diteliti oleh Lengkawati (2021) dan Sari \& Hidayat (2021) menunjukkan ada pengaruh terhadap keputusan pembelian. Hal tersebut melatari peneliti dalam melakukan penelitian terhadap keputusan pembelian Scarlett Whitening.

Dengan dasar tersebut, maka model penelitian ini dapat dilihat pada Gambar 1.

Gambar 1. Model Penelitian

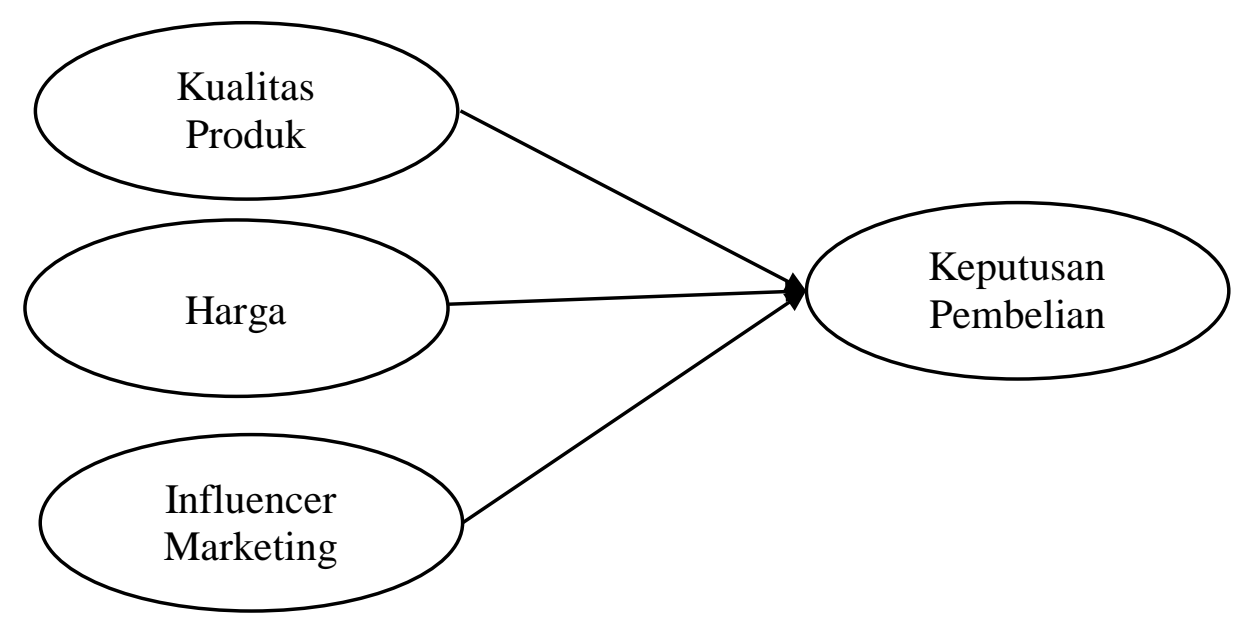

Sumber: Data diolah.

Adapun hipotesis dari penelitian ini adalah:

H1 : Diduga ada pengaruh pada variabel kualitas produk terhadap keputusan pembelian Scarlett Body Whitening di Kota Malang.

H2 : Diduga ada pengaruh pada variabel harga terhadap keputusan pembelian Scarlett Body Whitening di Kota Malang.

H3 : Diduga ada pengaruh pada variabel influencer marketing Rachel Vennya 
terhadap keputusan pembelian Scarlett Body Whitening di Kota Malang.

\section{Hasil Dan Pembahasan}

1. Uji Validitas

Instrumen penelitian dapat dikatan valid apabila nilai dari Sig.(2-tailed) setiap varibel penelitian terhadap variabel total kurang dari taraf signifikasi penelitian (Sig.(2-tailded) $<\alpha=0,05)$. Berdasarkan hasil dari uji validitas menyatakan bahwa semua item yang mengukur variabel-variabel penelitian memiliki R-hitung yang lebih besar dari R-tabel, begitupun nilai Sig.(2tailed) dari person correlation terhadap variabel total setiap item bernilai $0,000<0,05$ (taraf signifikasi atau $\alpha$ ). Maka dinyatakan bahwa instrument peneltian yaitu kuisioner yang digunakan untuk mengukur kualitas produk, harga, influencer marketing Rachel Vennya dan keputusan pembelian Scarlett Body Whitening di Kota Malang Valid atau Sah.

\section{Uji Reliabilitas}

Instrumen penelitian dapat dikatakan reliabel apabila nilai dari Cronbach's Alpha diketahui lebih besar dari 0,6. Berdasarkan hasil dari uji reliabilitas diketahui bahwa nilai Cronbach's Alpha dari setiap item yang mengukur variabel-variabel penelitian lebih besar dari 0,6. Hal ini menunjukkan bahwa instumen penelitian yaitu kuisioner yang digunakan untuk mengukur kualitas produk, harga, influencer makketing Rachel Vennya dan keputusan pembelian Scarlett Body Whitening di Kota Malang Reliabel atau Konsisten atau Handal.

\section{Uji Hipotesis}

a. Uji Determinasi

b. Berdasarkan Tabel 1 menunjukkan bahwa nilah $R$-Square sebesar 0,716. Menunjukkan bahwa sebesar 71,6\% Keputusan Pembelian Scarlet Body Whitening di Kota Malang dijelaskan oleh kualitas produk, harga dan influencer marketing Rachel Vennya. Sedangkan sisanya 100\% - 71,6\% = 
28,4\% dijelaskan oleh variabel lain yang tidak dipertimbangkan dalam penelitian ini.

Tabel 1. Uji Determinasi

\begin{tabular}{|c|c|c|c|c|c|}
\hline \multicolumn{6}{|c|}{ Model Summary } \\
\hline Model & $\mathrm{R}$ & R Square & $\begin{array}{l}\text { Adjusted R } \\
\text { Square }\end{array}$ & $\begin{array}{l}\text { Std. Error of the } \\
\text { Estimate }\end{array}$ & Durbin-Watson \\
\hline 1 & $.846^{a}$ & .716 & .709 & 1.956 & 2.110 \\
\hline
\end{tabular}

a. Predictors: (Constant), X3, X1, X2

b. Dependent Variable: $Y$

c. Uji F

Tabel 2. Uji F

\begin{tabular}{|c|c|c|c|c|c|c|}
\hline \multicolumn{7}{|c|}{ ANOVA $^{a}$} \\
\hline Model & & Sum of Squares & Df & Mean Square & $\mathrm{F}$ & Sig. \\
\hline \multirow[t]{3}{*}{1} & Regression & 1120.466 & 3 & 373.489 & 97.600 & $.000^{\mathrm{b}}$ \\
\hline & Residual & 443.901 & 116 & 3.827 & & \\
\hline & Total & 1564.367 & 119 & & & \\
\hline
\end{tabular}

a. Dependent Variable: $Y$

Predictors: (Constant), X3, X1, X2

Berdasarkan data Tabel 2 dapat diketahui bahwa nilai $\mathrm{F}$ hitung bernilai 97.600 dengan nilai Sig. sebesar 0,000. Sedangkan nilai F-tabel untuk nilai signifikasi atau $\alpha=0,05$; df1 $=3$; df $2=116$ sebesar 2.68. Karena nilai Fhitung > F-tabel $(97.600>2.68)$ dan Sig. $<\alpha(0,000<0,05)$. Artinya model regresi yang terbentuk memenuhi goodness of fit model atau model regresi yang terbentuk layak serta dapat digunakan untuk memprediksi keputusan pembelian Scarlett Body Whitening di Kota Malang.

d. Pembentukan Model Regresi

Pembentukan model regresi dilakukan dengan melakuakn Uji Regresi yang tersaji dalam Tabel 3. 
Tabel 3 Uji Regresi

\begin{tabular}{llr|r|r} 
& & \multicolumn{2}{c|}{$\begin{array}{c}\text { Unstandardized Coefficients } \\
\text { Model }\end{array}$} & $\begin{array}{c}\text { Standardized } \\
\text { Coefficients } \\
\text { Beta }\end{array}$ \\
\hline 1 & B & Std. Error & \\
\cline { 2 - 5 } & (Constant) & 2.964 & 1.043 & \\
\hline $\mathrm{X} 1$ & .381 & .058 & .514 \\
\hline $\mathrm{X} 2$ & .389 & .089 & .344 \\
\hline $\mathrm{X} 3$ & .047 & .041 & .068 \\
\hline
\end{tabular}

Berdasarkan nilai B maka dapat dibentuk model regresi linier berganda sebagai berikut :

$$
Y=2.964+0,381 X 1+0,389 X 2+0,047 X 3+\varepsilon
$$

Berdasarkan hasil dari model regresi yang terbentuk, dapat diketahui bahwa konstanta regresi bernilai positif, sebesar 2.964 yang artinya tanpa adanya X1 (kualitas produk), X2 (harga) dan X3 (influencer marketing Rachel Vennya) sebenarnya konsumen yang menjdi responden penelitian telah memiliki keputusan pembelian. Ini dikarenakan adanya factor lain yang menjadikan konsumen memutuskan pembelian. Koefisien regresi pada X1 (kualitas produk) bernilai positif sebesar 0,381. Artinya semakin tinggi kualitas produk maka semakin tinggi keputusan pembelian. Dan Adapun setiap 1 kenaikan satuan kualitas produk maka akan menaikkan keputusan pembelian sebesar 0,381 satuan. Koefisien regresi pada X2 (harga) bernilai positif sebesar 0,389. Artinya semakin tinggi harga maka semakin tinggi keputusan pembelian. Dan Adapun setiap 1 kenaikan satuan harga maka akan menaikkan keputusan pembelian sebesar 0,389 satuan. Koefisien regresi pada X3 (influencer marketing Rachel Vennya) bernilai positif sebesar 0,047. Artinya semakin tinggi review influencer Rachel Vennya maka semakin tinggi keputusan pembelian. Dan Adapun setiap 1 kenaikan satuan kualitas produk maka akan menaikkan keputusan pembelian sebesar 0,047 satuan. 
e. Uji T

\begin{tabular}{|c|c|c|c|c|c|c|c|c|}
\hline \multicolumn{9}{|c|}{$\begin{array}{l}\text { Tabel 4. Uji T } \\
\text { Coefficients }^{\mathrm{a}}\end{array}$} \\
\hline \multirow[b]{2}{*}{ Model } & & \multicolumn{2}{|c|}{$\begin{array}{l}\text { Unstandardized } \\
\text { Coefficients }\end{array}$} & \multirow{2}{*}{$\begin{array}{c}\text { Standardized } \\
\text { Coefficients } \\
\text { Beta } \\
\end{array}$} & \multirow[b]{2}{*}{$t$} & \multirow[b]{2}{*}{ Sig. } & \multicolumn{2}{|c|}{ Collinearity Statistics } \\
\hline & & $\mathrm{B}$ & Std. Error & & & & Tolerance & VIF \\
\hline 1 & (Constant) & 2.964 & 1.043 & & 2.841 & .005 & & \\
\hline & $\mathrm{X} 1$ & .381 & .058 & .514 & 6.576 & .000 & .401 & 2.494 \\
\hline & $\mathrm{X} 2$ & .389 & .089 & .344 & 4.356 & .000 & .392 & 2.552 \\
\hline & $\mathrm{X} 3$ & .047 & .041 & .068 & 1.140 & .257 & .697 & 1.434 \\
\hline
\end{tabular}

a. Dependent Variable: $Y$

Tabel 4 menunjukkan nilai t-tabel untuk taraf signifikasi 0,05 dan df 116 senilai 1.98063. Nilai t-hitung X1 (kualitas produk) sebesar 6.576 dengan nilai Sig. 0,000. Hal ini menunjukkan bahwa variabel kualitas produk nilai t-hitung tidak berada dalam rentang -t-tabel sampai +t-tabel (6.576 tidak berada dalam rentang -1.98063 sampai +1.98063$)$ dan Sig. $\mathrm{t}<\alpha(0,000<$ 0,05). Maka kualitas produk berpengaruh positif dan signifikan terhadap keputusan pembelian. Oleh karena itu hipotesis pertama penelitian (H1) yaitu " Kualitas Produk berpengaruh positif dan signifikan terhadap keputusan pembelian Scarlett Body Whitening di Kota Malang DITERIMA. Nilai t-hitung X2 (harga) sebesar 4.356 dengan nilai Sig. 0,000. Hal ini menunjukkan bahwa variabel kualitas produk nilai t-hitung tidak berada dalam rentang -t-tabel sampai +t-tabel (4.356 tidak berada dalam rentang 1.98063 sampai +1.98063$)$ dan Sig. $\mathrm{t}<\alpha(0,000<0,05)$. Maka harga berpengaruh positif dan signifikan terhadap keputusan pembelian. Oleh karena itu hipotesis pertama penelitian (H2) yaitu " Harga berpengaruh positif dan signifikan terhadap keputusan pembelian Scarlett Body Whitening di Kota Malang DITERIMA.

Nilai t-hitung X3 (influencer marketing Rachel Vennya) sebesar 1.140 dengan nilai Sig. 0,000. Hal ini menunjukkan bahwa variabel kualitas produk nilai t-hitung berada dalam rentang $-\mathrm{t}$-tabel sampai $+\mathrm{t}$-tabel $(1.140$ 
berada dalam rentang -1.98063 sampai +1.98063) dan Sig. $\mathrm{t}<\alpha(0,000<$ 0,05). Maka influencer marketing Rachel Vennya berpengaruh positif dan tidak signifikan terhadap keputusan pembelian. Oleh karena itu hipotesis pertama penelitian (H3) yaitu “ Influencer Marketing Rachel Vennya berpengaruh positif dan tidak signifikan terhadap keputusan pembelian Scarlett Body Whitening di Kota Malang DITOLAK.

\section{Pembahasan}

\section{Pengaruh kualitas produk terhadap keputusan pembelian scarlett}

\section{body whitening di kota Malang}

Kualitas produk diketahui berpengaruh secara positif dan signifikan terhadap keputusan pembelian Scarlett Body Whitening di Kota Malang. Artinya apabila kualitas produk semakin meningkat maka akan menyebabkan naiknya keputusan pembelian konsumen Scarlett Body Whitening di Kota Malang. Hal ini sesuai dengan (Setiawan, 2018); (Putri, 2021) dan (Tumbel \& Walangitan, 2021) yang menyatakan bahwa kualitas produk berpengaruh secara signifikan terhadap keputusan pembelian. Dari hasil instrument penelitian atau kuisioner, jumlah persentase setuju dan sangat setuju pada variabel kualitas produk dengan nilai tertinggi didapat dari penyataan X14 yaitu "Saya merasa produk Scarlett Body Whitening memiliki varian aroma yang menarik dibandingkan dengan produk lain". Sedangkan jumlah presentase terendah didapat dari pernyataan X11 yaitu "Saya merasa ada perubahan yang cukup cepat setelah saya menggunakan Scarlett Body Whitening pada tubuh saya". Ini dapat membuktikan bahwa responden sebagai konsumen Scarlett Body Whitening memilih produk Scarlett Body Whitening dikarenakan kualitas produk Scarlett Body Whitening pada varian aroma lebih unggul dibandingkan dengan merek lain.

\section{Pengaruh harga terhadap keputusan pembelian scarlett body whitening di kota Malang}


Harga telah diketahui berpengaruh secara positif dan signifikan terhadap keputusan pembelian Scarlett Body Whitening. Artinya setiap adanya kenaikan harga produk Scarlett Body Whitening maka akan menyebabkan peningkatan keputusan pembelian konsumen terhadap produk Scarlett Body Whitening. Hal ini dapat sesuai dengan (Purba, 2016); (Gunawan \& Agustin, 2019) dan (Putri, 2021) yang menyatakan bahwa harga berpengaruh positif dan signifikan terhadap keputusan pembelian. Dari hasil instrument penelitian atau kuisioner dalam penelitian ini dapat diketahui bahwa persentase item pernyataan yang membuktian variabel harga tertinggi terdapat pada pernyataan X22 yaitu "Saya merasa bahwa Scarlett Body Whitening memiliki harga yang berbanding lurus dengan kualitas". Sedangkan persentase terendah didapat dari pernyataan X23 yaitu "Saya merasa bahwa harga scarlett body whitening lebih terjangkau dibanding produk sejenis lainnya". Sehingga dapat dinyatakan bahwa harga produk Scarlett Body Whitening belum dapat dikategorikan terjangkau untuk beberapa konsumen, namun konsumen mempertimbangkan adanya harga yang berbanding lurus dengan kualitas produk Scarlett Body Whitening.

Pengaruh influencer marketing Rachel Vennya terhadap keputusan pembelian scarlett body whitening di kota Malang

Diketahui bahwa influencer marketing Rachel Vennya berpengaruh positif tidak signifikan terhadap keputusan pembelian Scarlett Body Whitening di Kota Malang. Artinya setiap influencer marketing Rachel Vennya tidak mempengaruhi setiap keputusan pembelian konsumen Scarlett Body Whitening di Kota Malang. Hal ini berbeda dengan (Cinthya Ryana Sari \& Agus Molana Hidayat, S.E., 2021) dan (Lengkawati, 2021) yang menyatakan bahwa influencer marketing berpengeruh secara positif dan signifikan terhadap keputusan pembelian. Perbedaan ini dapat disebabkan karena pada penelitian ini menggunakan Rachel Vennya sebagai subyek dari influencer marketing. Persentase tertinggi dalam item yang membuktikan variabel influencer marketing Rachel Vennya terdapat pada pernyataan Y2 yaitu "Saya percaya bahwa review yang dilakukan Rachel 
Vennya terhadap produk Scarlett Body Whitening itu sesuai kenyataan”. Sedangkan persentase terendah terdapat pada pernyataan Y5 yaitu "Saya merasa terbantu dengan adanya review Rachel Vennya untuk mengetahui produk Scarlett Body Whitening". Hal ini membuktikan bahwa walaupun review yang dilakukan oleh Rachel Vennya terbukti sesuai dengan kenyatan, namun informasi yang diberikan belum cukup membantu para konsumen mengetahui produk Scarlett Body Whitening. Hal lain yang menyebabkan influencer marketing Rachel Vennya adalah untuk mempertimbangkan keputusan pembelian Scarlett Body Whitening para konsumen tidak terlalu memperhatikan influencer dari Scarlet Body Whitening. Konsumen lebih memperhatikan hal lain seperti kualitas produk, harga dan factor lain yang tidak dipertimbangkan dalam penelitian ini.

\section{Kesimpulan}

Dari hasil dan pembahasan pada penelitian ini maka dapat disimpulkan bahwa Kualitas Produk sebagai variabel(X1) dan Harga sebagai variabel(X2) diketahui berpengaruh secara positif dan signifikan terhadap Keputusan Pembelian sebagai variabel(Y) Scarlett Body Whitening di Kota Malang. Sedangkan Influencer Marketing Rachel Vennya sebagai variabel(X3) diketahui berpengaruh secara positif dan tidak signifikan terhadap Keputusan Pembelian sebagai variabel(Y) Scarlett Body Whitening di Kota Malang.

Keterbasan yang dihadapi oleh peneliti dalam penelitian ini adalah pada saat pengambilan data melalui pembagikan kuisioner kepada para responden karena pada tahap ini terkadang para responden tidak mengisi kuisioner sesuai dengan pendapat masing-masing dari para responden. Selain itu, ternyata salah satu variabel bebas yang diangkat oleh peneliti tidak mampu memberikan pengaruh terhadap variabel terikatnya. Sehingga diharapkan untuk peneliti yang akan datang tetap melakukan penelitian berkelanjutan untuk menilai perubahan perilaku konsumen terutama pada keputusan pembelian. Serta diharapkan bagi peneliti selanjutnya dapat 
menambahkan variabel bebas lain yang dapat mempengaruhi variabel terikat dalam penelitian ini.

\section{DAFTAR PUSTAKA}

Cinthya Ryana Sari, \& Agus Molana Hidayat, S.E., M. S. (2021). Pengaruh Influencer Marketing Dan Kualitas Produk Terhadap Universitas Telkom the Influence of Influencer Marketing and Product Quality on Purchasing Decisions At Uniqlo. E-Proceeding of Management, 8(2), 1361-1368.

Gunawan, T., \& Agustin, S. (2019). PENGARUH KUALITAS PRODUK, HARGA, PROMOSI DAN CITRA MEREK TERHADAP KEPUTUSAN PEMBELIAN. Ecobisma (Jurnal Ekonomi, Bisnis Dan Manajemen), 4(2), 1725. https://doi.org/10.36987/ecobi.v6i2.1

Lengkawati, A. S. (2021). Pengaruh Influencer Marketing Terhadap Keputusan Pembelian. Prismakom, 18(1), 33-38. http://www.jurnal.stieyasaanggana.ac.id/index.php/yasaanggana/article/view/ 69

Purba, N. (2016). Pengaruh Bauran Pemasaran ( Kualitas Produk , Harga , Promosi. 1-9.

Putri, R. M. dan B. I. (2021). Pengaruh Harga, Kualitas Produk, Dan Celebrity Endorser Terhadap Minat Beli Produk Scarlett Whitening (Studi Kasus Pada Perempuan Di Surakarta). Jurnal Ekobis Dewantara, 4(2), 78-88.

Setiawan, M. A. (2018). PENGARUH KUALITAS PRODUK, HARGA, DAN PROMOSI TERHADAP KEPUTUSAN PEMBELIAN MOBIL BEKAS DI SAPUTRA MOTOR Aniek Wahyuati Sekolah Tinggi Ilmu Ekonomi Indonesia (STIESIA) Surabaya.

Tumbel, N. A. M. T. M., \& Walangitan, O. C. (2021). Pengaruh Kualitas Produk terhadap Keputusan Pembelian Skincare Scarlett Whitening pada Platform Digital. Productivity, 2(4), 272-275. https://ejournal.unsrat.ac.id/index.php/productivity/article/view/34831 